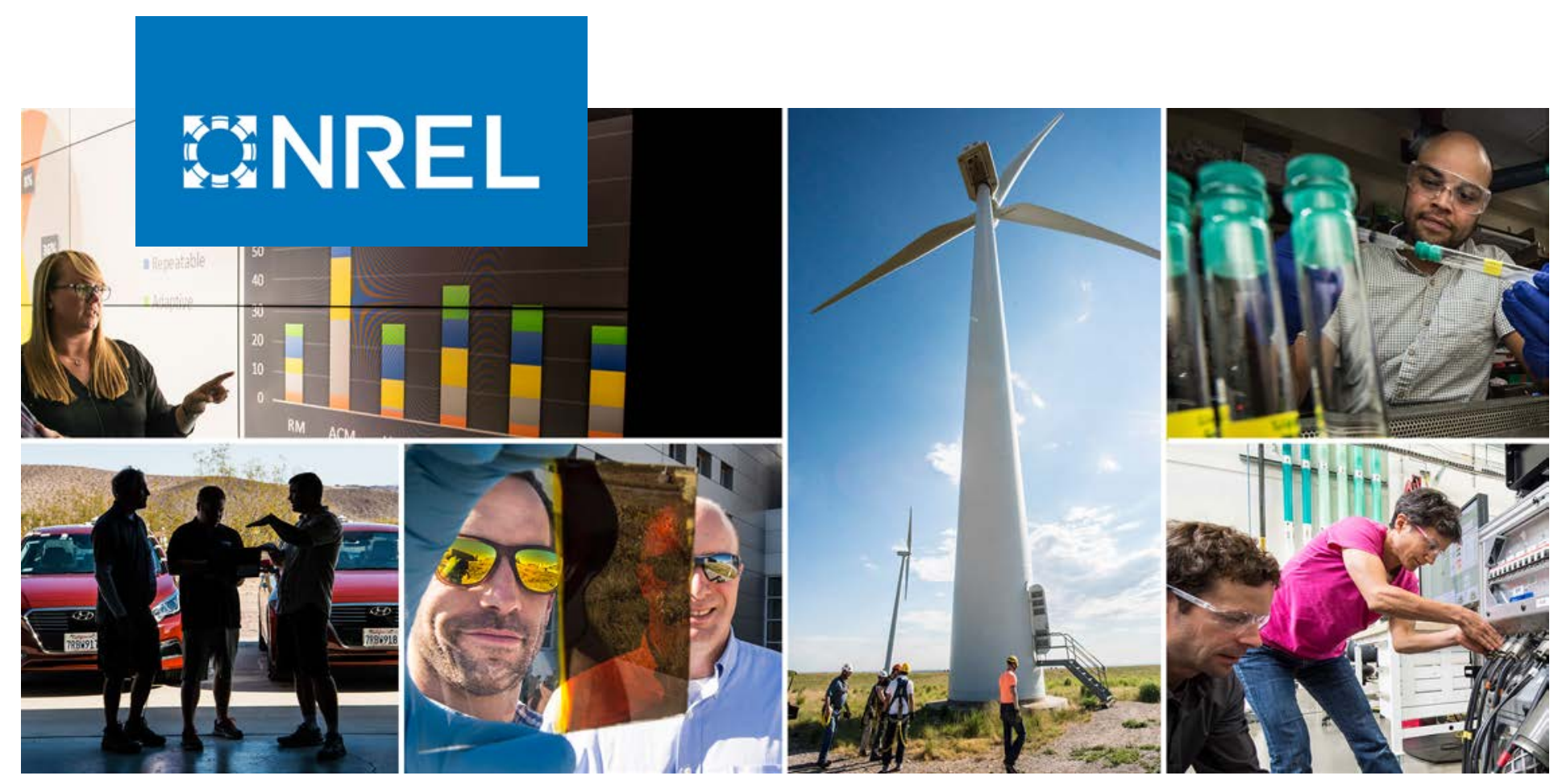

\title{
Historical Comparison of Capacity Build Decisions from the Regional Energy Deployment System (ReEDS) Model
}

Wesley Cole and Nina Vincent

National Renewable Energy Laboratory

NREL is a national laboratory of the U.S. Department of Energy Office of Energy Efficiency \& Renewable Energy

Operated by the Alliance for Sustainable Energy, LLC

This report is available at no cost from the National Renewable Energy Laboratory (NREL) at www.nrel.gov/publications.
Technical Report

NREL/TP-6A20-71916

February 2019 


\title{
GNREL
}

\section{Historical Comparison of Capacity Build Decisions from the Regional Energy Deployment System (ReEDS) Model}

\author{
Wesley Cole and Nina Vincent
}

National Renewable Energy Laboratory

\section{Suggested Citation}

Cole, Wesley and Nina Vincent. 2019. Historical Comparison of Capacity Build Decisions from the Regional Energy Deployment System (ReEDS) Model. Golden, CO: National Renewable Energy Laboratory. NREL/TP-6A20-71916. https://www.nrel.gov/docs/fy19osti/71916.pdf.

NREL is a national laboratory of the U.S. Department of Energy Office of Energy Efficiency \& Renewable Energy Operated by the Alliance for Sustainable Energy, LLC

This report is available at no cost from the National Renewable Energy Laboratory (NREL) at www.nrel.gov/publications.

Contract No. DE-AC36-08GO28308
Technical Report NREL/TP-6A20-71916

February 2019

National Renewable Energy Laboratory 15013 Denver West Parkway Golden, CO 80401 303-275-3000 • www.nrel.gov 


\section{NOTICE}

This work was authored by the National Renewable Energy Laboratory, operated by Alliance for Sustainable Energy, LLC, for the U.S. Department of Energy (DOE) under Contract No. DE-AC36-08GO28308. Funding provided by the U.S. Department of Energy Office of Energy Efficiency and Renewable Energy Solar Energy Technologies Office. The views expressed herein do not necessarily represent the views of the DOE or the U.S. Government.

This report is available at no cost from the National Renewable Energy Laboratory (NREL) at www.nrel.gov/publications.

U.S. Department of Energy (DOE) reports produced after 1991 and a growing number of pre-1991 documents are available free via www.OSTI.gov.

Cover Photos by Dennis Schroeder: (clockwise, left to right) NREL 51934, NREL 45897, NREL 42160, NREL 45891, NREL 48097, NREL 46526.

NREL prints on paper that contains recycled content. 


\section{Acknowledgments}

We are grateful to ReEDS modeling team for their input on this work. We also thank Kelly Eurek (NREL), Rebecca Jones-Albertus (EERE), Trieu Mai (NREL), Ryan Sims (EPA), and Dan Steinberg (NREL) for providing feedback on this report. This report was funded by the EERE Solar Energy Technologies Office under contract number DE-AC36-08GO28308. All errors and omissions are the sole responsibility of the authors. 


\section{List of Acronyms}

$\begin{array}{ll}\text { AEO } & \text { Annual Energy Outlook } \\ \text { CAES } & \text { compressed-air energy storage } \\ \text { CSP } & \text { concentrating solar power } \\ \text { dGen } & \text { Distributed Generation model } \\ \text { DOE } & \text { Department of Energy } \\ \text { NERC } & \text { North American Electric Reliability Corporation } \\ \text { NG-CC } & \text { natural gas combined cycle } \\ \text { NG-CT } & \text { natural gas combustion turbine } \\ \text { NREL } & \text { National Renewable Energy Laboratory } \\ \text { OGS } & \text { oil/gas steam } \\ \text { PRM } & \text { planning reserve margin } \\ \text { PV } & \text { photovoltaic } \\ \text { REC } & \text { renewable energy credit } \\ \text { ReEDS } & \text { Regional Energy Deployment System } \\ \text { RPS } & \text { renewable portfolio standard } \\ \text { WACC } & \text { weighted-average cost of capital }\end{array}$




\section{Executive Summary}

The Regional Energy Deployment System (ReEDS) capacity expansion model is frequently used to project the evolution of the U.S. power sector under a wide range of conditions. However, the model's capacity expansion decisions have never been evaluated against historical capacity expansion decisions. In this work, we perform a model validation exercise, comparing capacity expansion decision from ReEDS for 2010-2016 against the actual buildout of the electricity sector. We find that with three key adjustments ReEDS is able to reproduce national-level results with reasonably high accuracy (see Figure ES-1). Those three adjustments are to use historical average planning reserve margins instead of the NERC-recommended reserve margin levels, using actual financing costs rather than long-term average financing costs, and disallowing the lowest-cost hydropower upgrades, geothermal sites, and compress-air energy storage sites. We also compare the ReEDS results at a state-level and find that state-level results can be better represented by including a hurdle rate (cost penalty) for transferring power between regions. The improved results with that hurdle rate indicate that the ReEDS transmission representation is likely not sufficiently stringent and should be improved. Overall these results show that with the improvements described above, ReEDS can effectively reproduce historical capacity additions, which increases our confidence in using the model in making forward-looking projections.

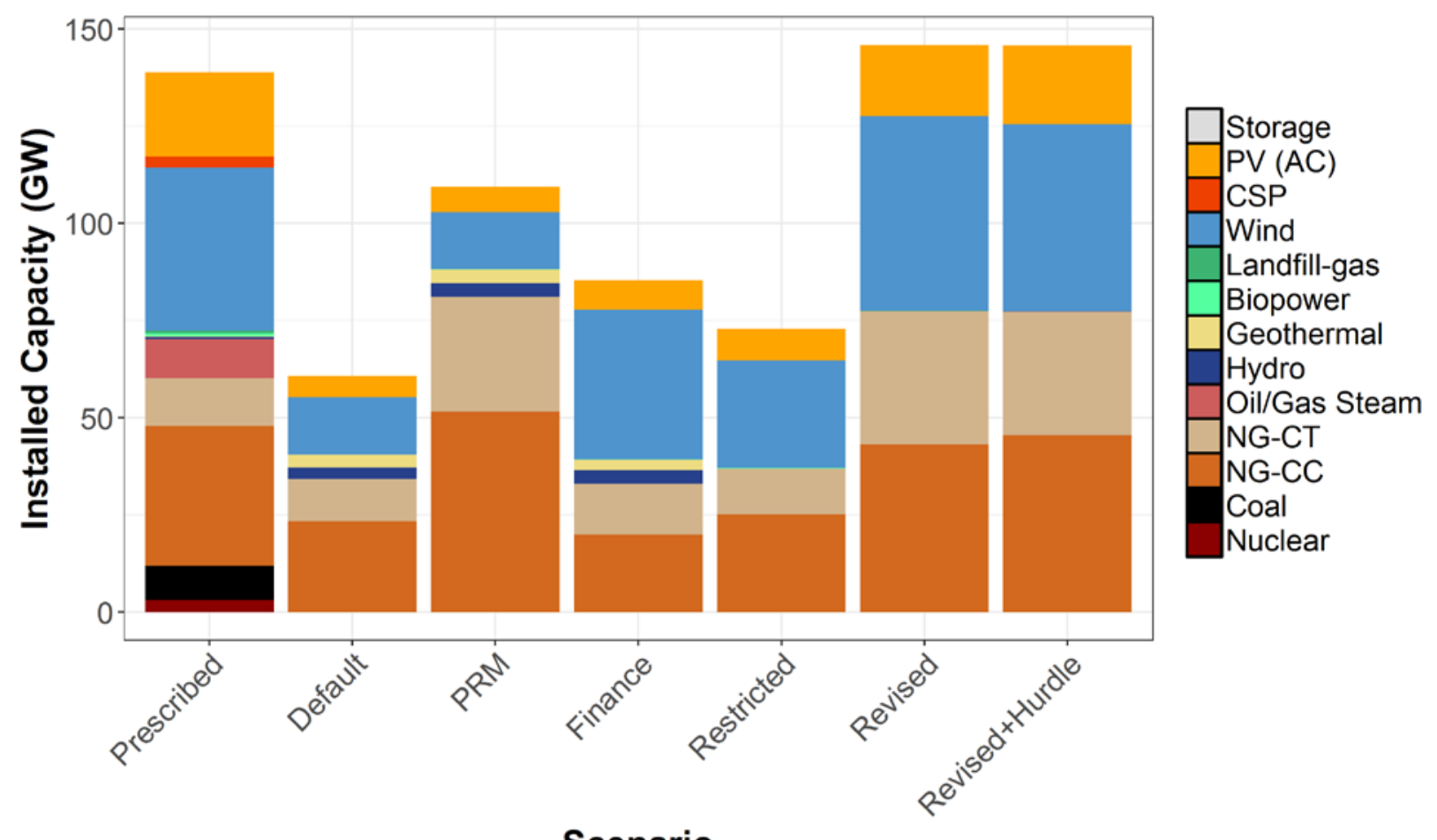

\section{Scenario}

Figure ES-1. Capacity installed from 2010-2016. "Prescribed" uses historical builds, "Default" uses the ReEDS version 2017 default inputs, "PRM" adjusts the reserve margins to more closely match historical levels, "Finance" adjusts the financing inputs to better match historical levels, "Restricted" disallows new hydropower, geothermal, and compressed air energy storage, "Revised" combines the PRM, Finance, and Restricted changes, and "Revised+Hurdle" adds a hurdle rate to the Revised scenario. Additional details are in Section 3. 


\section{Table of Contents}

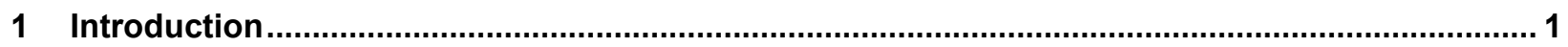

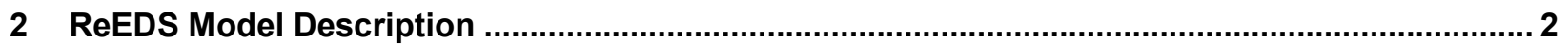

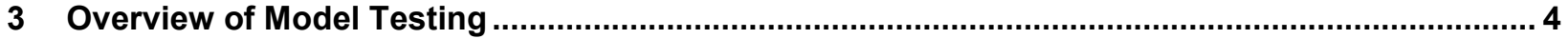

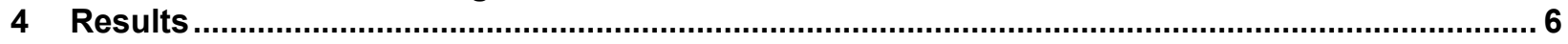

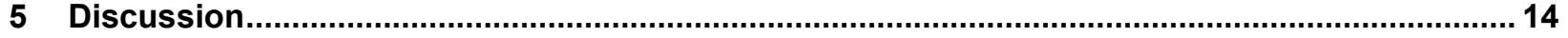

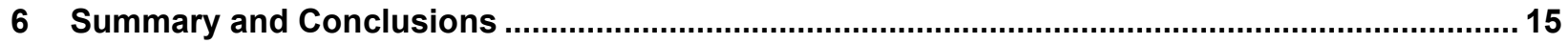

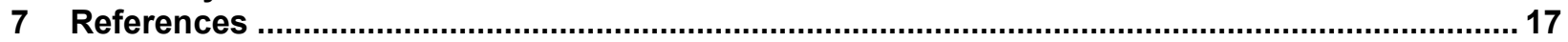

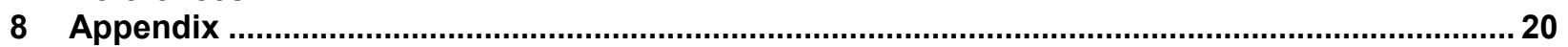




\section{Introduction}

The Regional Energy Deployment System (ReEDS) model is a large-scale capacity expansion model of the electricity sector. ReEDS has been used for a wide variety of electricity-sector studies including the SunShot Vision Study (DOE 2012) and subsequent SunShot 2030 analysis work (Cole, Frew, et al. 2017), the Wind Vision Study (DOE 2015), the Hydropower Vision Study (DOE 2016), analysis of tax credit extensions (Mai, Cole, et al. 2016), renewable portfolio standards analysis (Mai, Wiser, et al. 2016), Clean Power Plan analysis (Cole et al. 2015), crossborder trade analysis (Beiter, Cole, and Steinberg 2017), high penetration renewable energy analysis (Mai et al. 2012), rooftop PV tariff and deployment impacts (Cole et al. 2016; Gagnon et al. 2017), and assessing the impact of clean energy research and development on power sector evolution (Donohoo-Vallett et al. 2017). ${ }^{1}$

The ReEDS model has been under continuous development at NREL for over 15 years (Short et al. 2003; Eurek et al. 2016). One key piece of model development and use is model verification and validation. Verification and validation are used to ensure a model has sufficient accuracy that it can be used to analyze the real system it attempts to represent. Because capacity expansion decisions happen over long time scales, it is challenging to validate planning models such as ReEDS, and to date model validation has not been feasible because the ReEDS model has not been used over a sufficient number of historical years to perform a validation exercise. However, with ReEDS currently solving from 2010-2050, enough time has now passed that we have sufficient historical data to attempt a comparison between ReEDS model outputs and actual historical builds.

Validating large-scale, long-term planning models is challenging for a number of reasons. First, models such as ReEDS are very large. For example, in any given solve year ReEDS typically has 3-4 million decision variables, and attempting to validate results across all variables would not be practical. Second, compiling robust data for historical years can be challenging, making comparisons with model outputs an imperfect exercise. Differences in reporting requirements coupled with the wide variety of entities or organizations who interact with the power sector make it difficult to create fully accurate historical data sets of simple capacity expansion model inputs such as electricity demand, electricity generator costs, and policy requirements. Third, investment decisions in the power sector are made both on actual realized values as well as perceptions or anticipation of how those values might change over time. For example, a utility or investor may consider expected (but not yet enacted) policies when evaluating alternative investment options.

The purpose of this paper is to evaluate the performance of ReEDS in making capacity build decisions. We focus here on only new build decisions, and do not explicitly consider operational decisions, though any new build decisions are obviously impacted by how the model chooses to operate the generators. There is separate ongoing work that is evaluating the dispatch and operational decisions within ReEDS. We first provide a brief description of the ReEDS model (Section 2), then outline our model testing procedure (Section 3) and show the ReEDS results compared to historical results (Section 4). We conclude with a summary and set of recommendations for future model improvements (Section 5).

\footnotetext{
${ }^{1}$ See https://www.nrel.gov/analysis/reeds/publications.html for a complete list of publications using ReEDS. Over 50 publications were supported using the ReEDS model from 2014-2017.
} 


\section{ReEDS Model Description}

ReEDS simulates the expansion and operation of generation and transmission capacity from present day to 2050 across the contiguous United States (see Eurek et al. (2016) and Cole et al. (2017) for detailed descriptions of ReEDS). ${ }^{2}$ ReEDS selects the regional mix of technologies that meets physical and policy requirements of the electric sector at least cost. Model results are based on total system costs, which account for the type and location of fossil, nuclear, renewable, and storage resource development; the transmission infrastructure expansion requirements of those installations; and the generator dispatch and fuel needed to satisfy regional electricity consumption requirements and maintain grid system adequacy. ReEDS also accounts for technology, resource, and policy considerations such as state renewable portfolio standards (RPS). Because ReEDS does not explicitly model distributed generation, we also use the Distributed Generation (dGen) model (Sigrin et al. 2016), a consumer adoption model for the contiguous U.S. rooftop, distributed PV market.

The primary outputs from ReEDS include the amount, type, year, and location of generator capacity; generation from each technology; storage capacity expansion; and transmission capacity expansion needed to satisfy regional electricity consumption requirements and maintain grid system adequacy. The generation and storage technologies modeled in ReEDS include coalfired (pulverized coal with and without scrubbers, biomass cofiring, and integrated gasification combined cycle with and without carbon capture and storage), natural-gas-fired combined cycle (NG-CC) and combustion turbine (NG-CT), oil/gas steam (OGS), nuclear, wind (land-based and offshore), biopower, geothermal, hydropower, utility PV, concentrating solar power (CSP) with and without thermal energy storage, pumped-hydropower storage, compressed-air energy storage (CAES), and utility-scale batteries.

ReEDS represents the electric sector with high spatial resolution to enable comparative electricity sector cost evaluation based on local costs, regional pricing, and the relative value of geographically and temporally constrained renewable power sources. The model divides the contiguous United States into 134 "balancing area" regions, wherein electricity supply and consumption are balanced and planning reserves are enforced. ReEDS also characterizes the quality, variability, uncertainty, and geographic resource constraints of renewable resources across these 134 regions; wind and CSP technologies are further characterized into more resolved sub-regions (see Figure 1). Long-distance transmission is represented as corridors between most adjacent or near-adjacent modeling balancing area regions, and ReEDS models both existing and new transmission capacity on these inter-region corridors. ReEDS also models the intra-region "spur line" transmission costs required to connect renewable capacity to substations or load centers.

\footnotetext{
${ }^{2}$ This work uses the 2017 version of the ReEDS model, consistent with Cole et al. (2017).
} 


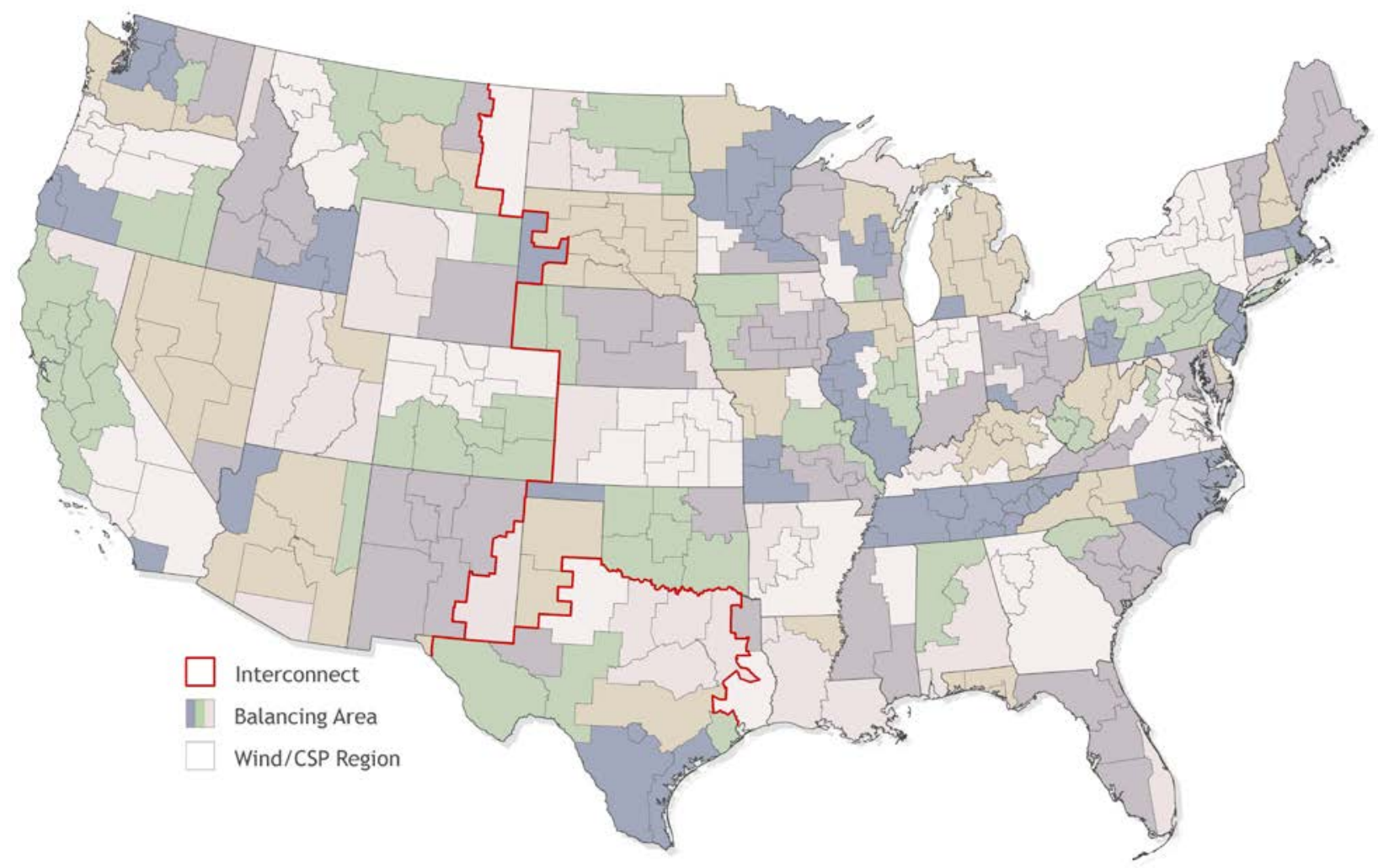

Figure 1. Map of the ReEDS balancing areas including wind and CSP resource subregions

ReEDS is temporally resolved into 17 "time slices" that each reflect a set of hours in each day within a season. For each two-year solution interval from 2010 to 2050, ReEDS dispatches all generation in each of these 17 time slices to capture seasonal and diurnal electricity load and renewable generation profiles. ReEDS represents generation, operating reserves, and curtailment at this 17 time slice resolution. Additionally, ReEDS uses hourly wind, PV and load profiles to estimate the contribution of wind and PV to meet peak demand requirements (Frew et al. 2017).

Specific elements of ReEDS that are especially relevant for this model validation exercise include:

- ReEDS is a sequential model that only solves for even years. Although ReEDS solves from 2010-2050, we can only compare years 2010, 2012, 2014, and 2016 to historical data.

- ReEDS has limited foresight to future conditions. ReEDS has foresight into future natural gas or carbon prices (if applicable), but not into load growth, policy timelines (such as the production or investment tax credit), or technology cost changes.

- ReEDS is a purely linear model.

- ReEDS uses system-wide optimization based on minimizing overall system costs. It does not model individual actors or profit-maximizing agents.

- ReEDS does not currently have the capability to convert units from one type to another (e.g., convert a coal plant to run on natural gas) or to uprate units. 


\section{Overview of Model Testing}

For historical years (2010-2016), we prescribe all capacity additions in ReEDS according to the online dates, technology types, locations, and capacities from the ABB Velocity Suite Database (ABB 2017). Thus, ReEDS is not allowed to make investment decisions until the 2018 solve year. ${ }^{3}$ In order to perform this model testing exercise, we do not enforce those prescriptive capacity additions and gave ReEDS the ability to begin making investment decisions in 2010. By doing this, all capacity additions are selected through the ReEDS optimization. However, several other model features were left unchanged as described below:

Retirements: ReEDS retirements are prescribed based on actual retirement dates, announced retirements, or on lifetime. Because retirements are not model decisions, we do not change our treatment of retirements for our test scenarios, and therefore retirements will be represented with full accuracy.

Transmission: Transmission capacity additions are prescribed through 2016. Those prescriptive capacity additions were left unchanged for these model tests.

Historical data: Historical data for conventional generator cost and performance, load growth, and fuel costs were taken from EIA Annual Energy Outlooks (AEO) 2012-2017 (each AEO has historical data from the two years prior) at the national (for generator cost and performance) or census region level. No attempt was made to gather more granular data (e.g., state-level demand data, hub-level fuel prices), and data were not disaggregated below the annual levels reported in the AEOs.

Rooftop PV: Rooftop PV is input exogenously into ReEDS based on projections from the dGen model (Sigrin et al. 2016). Because this model testing only focuses on the ReEDS model and not on dGen, we leave the rooftop PV projections as exogenous.

Historical cost and performance data for wind were taken from Wiser and Bolinger (2017) and for Solar PV from Fu et al. (2017) and Bolinger, Seel, and LaCommare (2017). The production and investment tax credits were implemented for eligible technologies for all years from 20102016. Because ReEDS only has limited foresight, no attempt was made to capture anticipated changes in the market, such as the expiration of tax credit policies or that load might grow at a greater rate than what was observed empirically.

To perform the model testing, we ran 7 scenarios in ReEDS, solving only for years 2010-2016:

Prescribed. This scenario uses the prescribed new builds from the ABB Velocity Suite Database (ABB 2017) and does not allow ReEDS to build new generators. This scenario serves as the scenario with the "true" buildout of capacity, and it is the only scenario in which historical builds are enforced.

Default. This scenario uses the default settings in ReEDS as described above. In other words, this scenario shows the ReEDS buildout when ReEDS makes all the investment decisions from 2010-2016 without changing any model inputs or functionality.

\footnotetext{
${ }^{3}$ For model feasibility purposes, new natural gas combustion turbine plants are allowed in historical years, but nonprescribed combustion turbine capacity is small.
} 
PRM. This scenario uses the observed long-term average (1990-2016) planning reserve margin (PRM) instead of the NERC recommended levels for PRM. Figure 2 shows how the PRMs differ when using this long-term average PRM. ${ }^{4}$

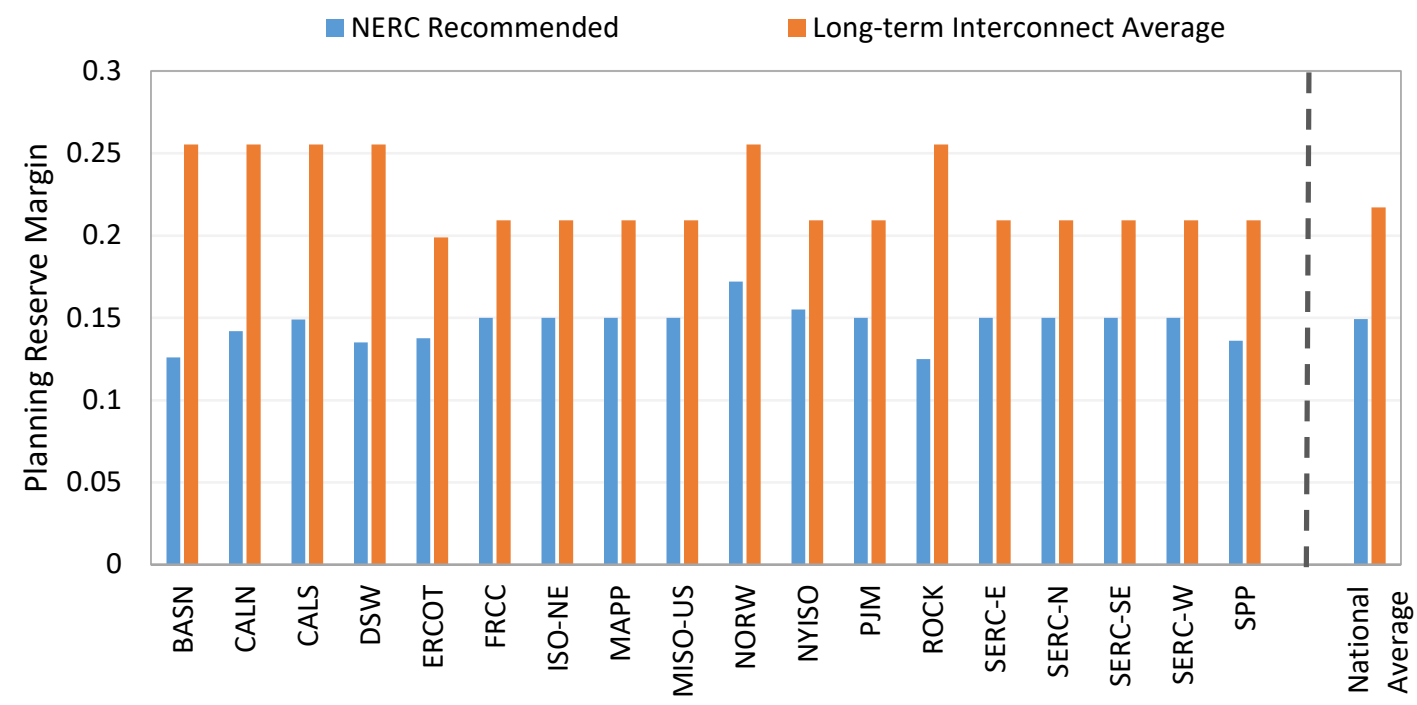

Figure 2. Planning reserve margin for the approximate NERC regions within ReEDS. See Figure 11 in the Appendix for a map showing the region definitions.

Financing. This scenario uses the current estimates for rate of return on equity and interest rates, taken from the 2017 Annual Technology Baseline (NREL 2017). These financing values result in a nominal weighted average cost of capital (WACC) of $5.4 \%$. The Default scenario, on the other hand, uses long-term averages financing values that result in a nominal WACC of $8.1 \%$.

Restricted. This scenario disallows the buildout of new geothermal plants, hydropower upgrades, and CAES plants.

Revised. This scenario combines the PRM, Financing, and Restricted scenario settings into a single scenario. In other words, the Revised scenario uses the long-term average PRM, the current financing values with a WACC of 5.4\%, and does not allow new geothermal, hydropower upgrades, and CAES.

Revised+Hurdle. This scenario is the same as the Revised scenario, except that it also includes a \$10/MWh hurdle rate for transferring power between ReEDS balancing areas (see Figure 1). The hurdle rate increases the cost of moving power between regions.

The comparison of the results focuses on the Prescribed, Revised, and Revised+Hurdle scenarios, but all scenarios are shown. No attempt was made to further harmonize any of these inputs with actual historical data. For example, PRMs and financing rates varied each year from 2010-2016, but we apply the same PRM and financing rates across all years. Similarly, we do not address specific changes in load growth, generator cost and performance, state and local incentives (other than those already included in the model), and other model input assumptions that could change from one year to the next.

\footnotetext{
${ }^{4}$ See Reimers, Cole, and Frew (under review) for more details.
} 


\section{Results}

The result of allowing ReEDS to make all generator investment decisions is shown in Figure 3 and Figure 4. On an aggregate basis (Figure 3) there is relatively little difference between the Prescribed scenario and the two Revised scenarios. That is because less than $15 \%$ of the total capacity at the end of 2016 was built between 2010 and 2016. Figure 4 shows just the new capacity additions from 2010-2016 in the Prescribed and Revised scenarios. The overall capacity added to the system is approximately $5 \%$ greater in the Revised scenarios.

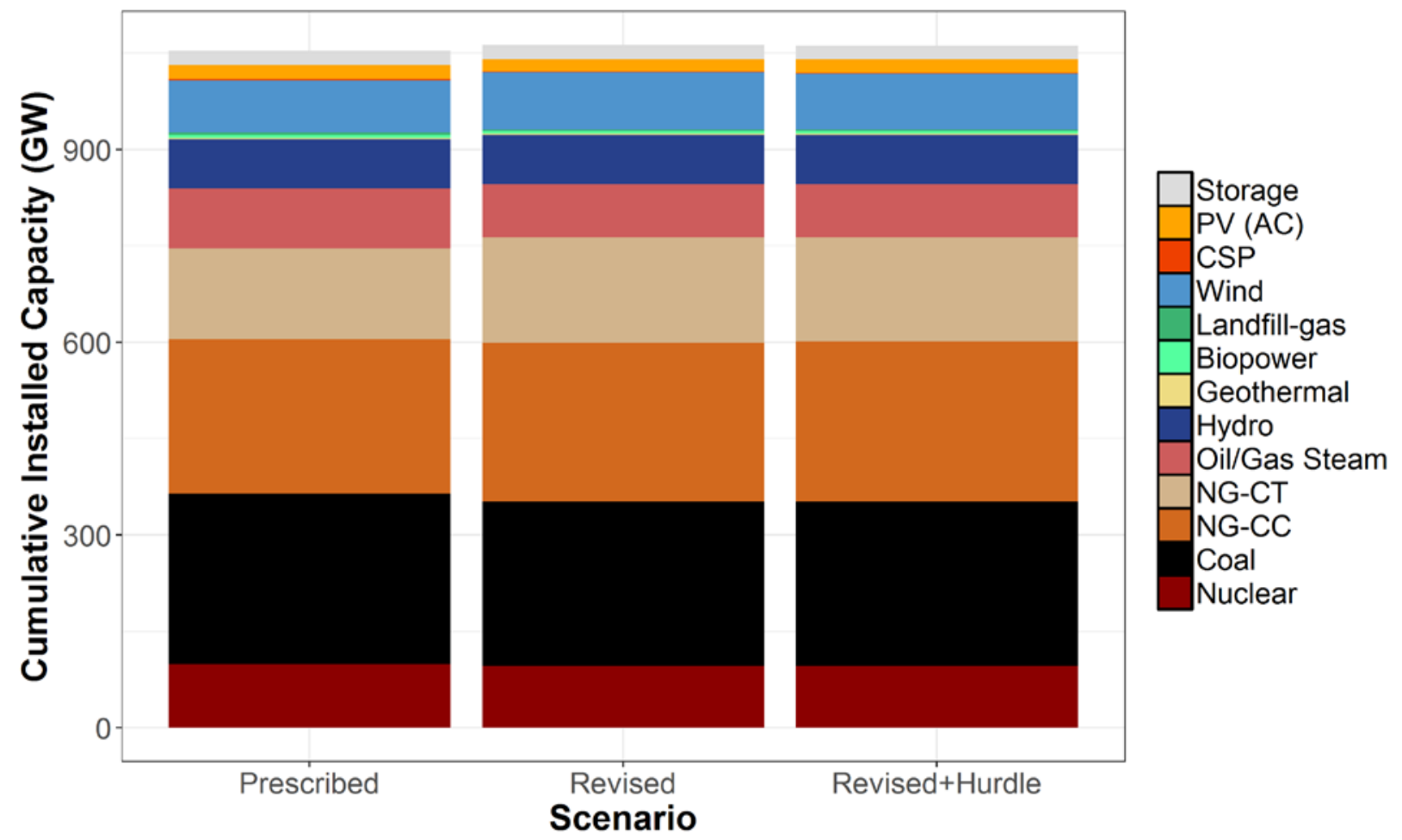

Figure 3. Final installed capacity by technology and scenario 


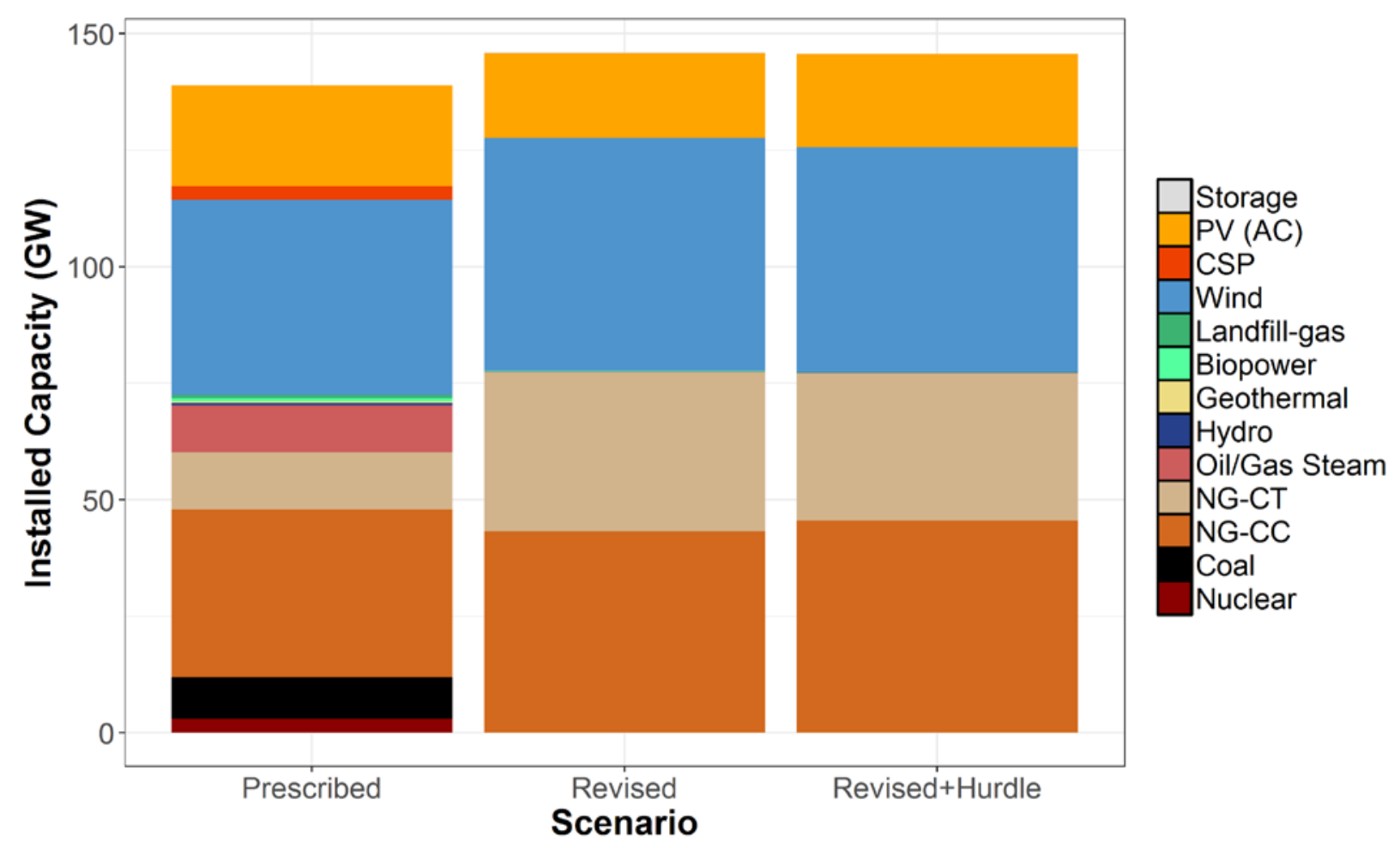

Figure 4. Capacity installed from 2010-2016

Figure 5 and Figure 6 provide the same information as Figure 3 and Figure 4, respectively, but compare the results by technology. Again, on an aggregate basis (Figure 5) the technologies are well aligned, but one can begin to see differences more easily when comparing only the new builds (Figure 6). For example, coal and nuclear plant options are not chosen by ReEDS. The new nuclear capacity is a combination of plant uprates and the second unit of the Watts Barr nuclear power plant that came online in 2016. The Watt Barr plant began construction in 1973, but was placed on hold for many years, and thus the cost and incentives for completing the plant are different than the inputs assumed in ReEDS. And ReEDS does not currently have the capability to model nuclear power plant uprates, so that shortcoming is highlighted here. The coal plants that came online (and that ReEDS did not build in the Revised scenarios) reflect that ReEDS does not have hindsight of conditions before 2010 such as high natural gas prices and demand growth that could have made new coal units a cost-effective option. Instead of these coal and nuclear plants, ReEDS chooses natural gas combined cycle plants. From Figure 6, the sum of the NG-CC, coal, and nuclear capacity in the Prescribed scenario is approximately equal to the NG-CC capacity in the Revised scenarios. 


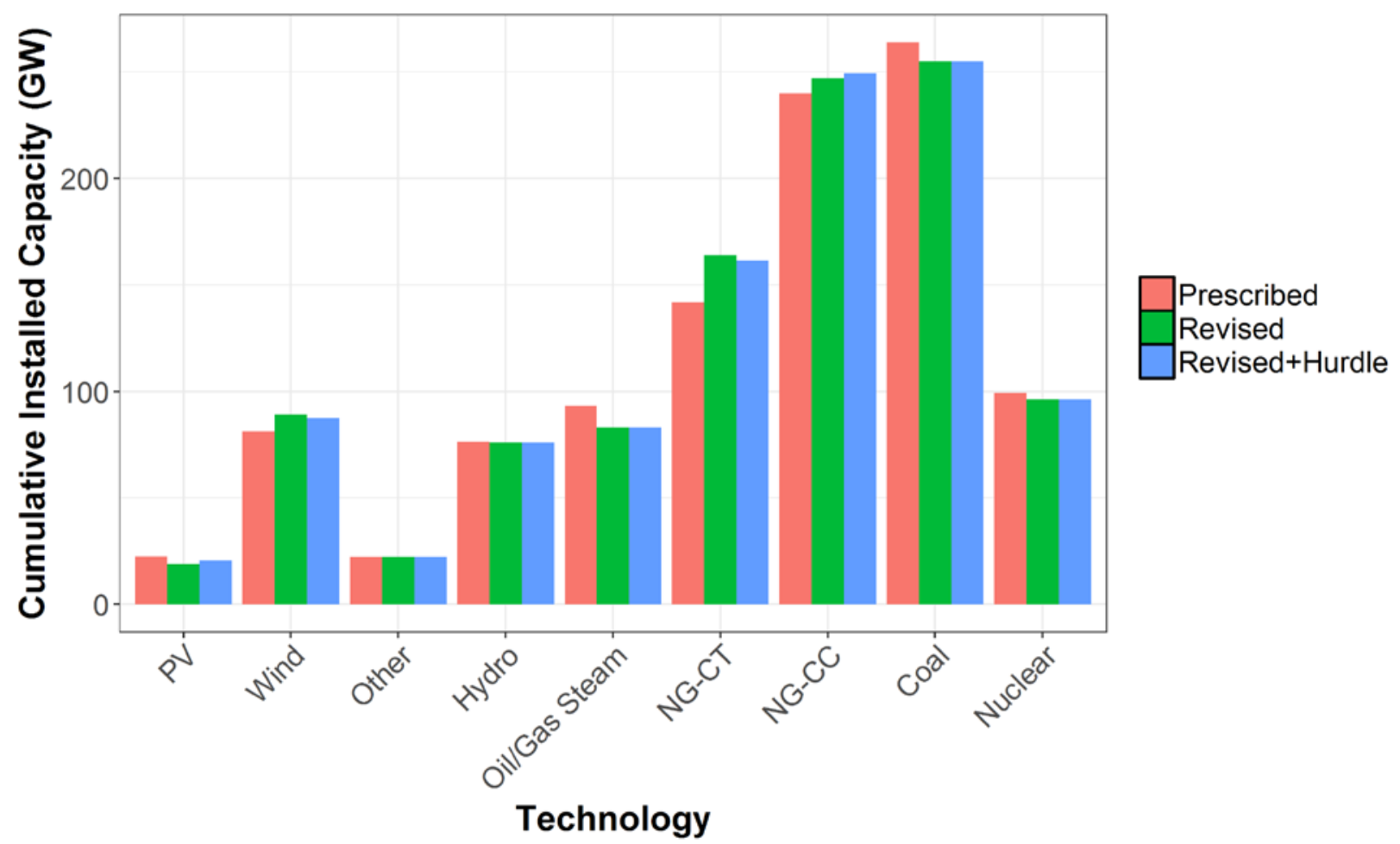

Figure 5. Final installed capacity in 2016 by technology

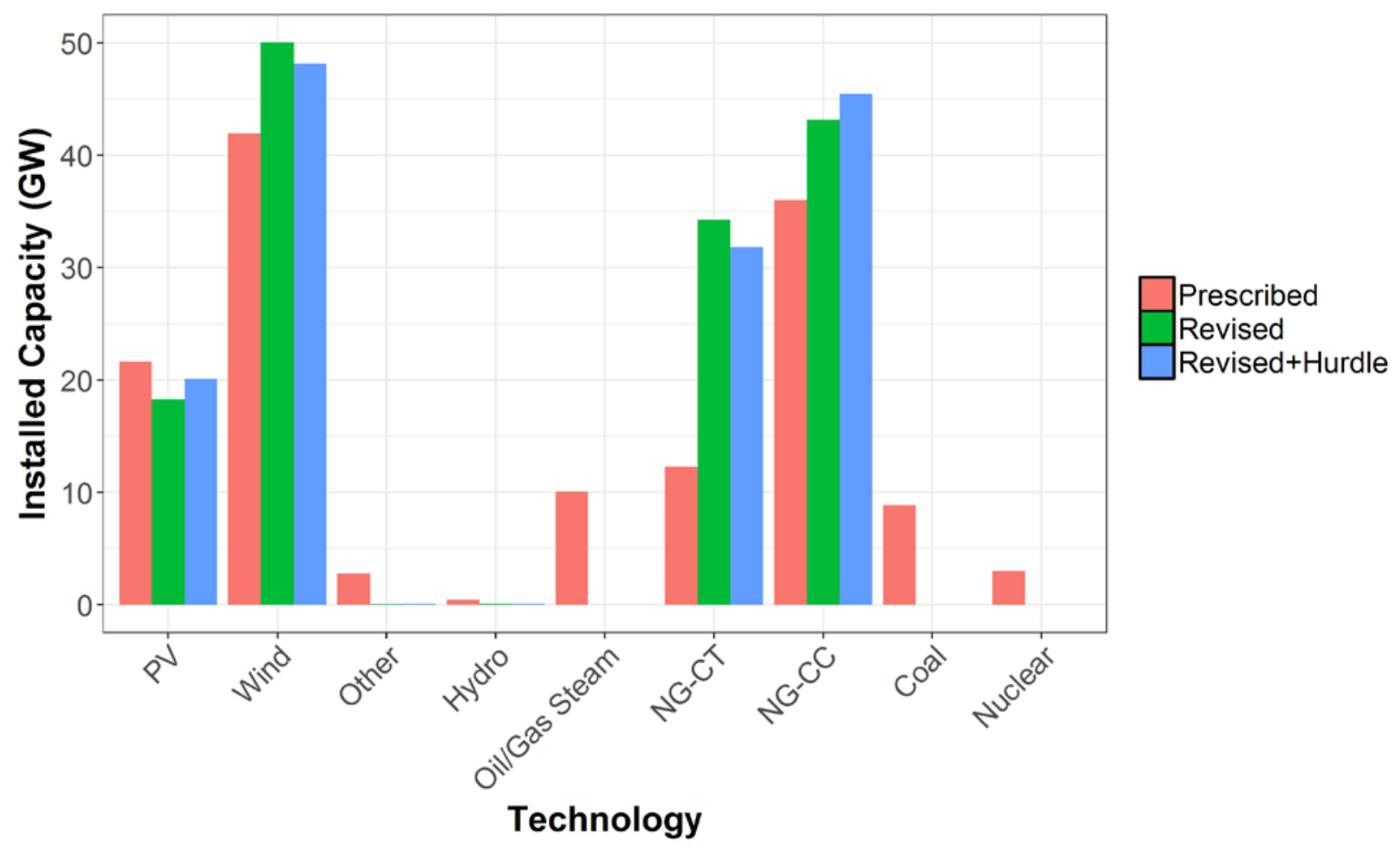

Figure 6. Capacity added in 2010-2016 by technology

Additionally, the results from Figure 6 highlight other aspects of ReEDS operation. The $10 \mathrm{GW}$ of OGS plants are largely coal plants that were converted to run on natural gas, thus becoming 
natural gas steam plants. ReEDS does not currently have an option to convert coal-fired plants to gas-fired plants, and thus misses these builds. Additionally, ReEDS NG-CT capacity is nearly triple that of what was deployed historically. One reason for that is that ReEDS builds NG-CT capacity instead of the OGS capacity. Another reason is that ReEDS assumes all peak demands are coincident, and thus the peak demand is ReEDS is likely higher than actual peak demand, and therefore ReEDS builds additional NG-CT capacity to meet that higher peak demand requirement. ReEDS also underestimates the "Other" technology category, which includes biomass, land-fill gas, geothermal, and CSP. Geothermal was disallowed by definition in the Revised scenario, and the updated geothermal supply curves from the forthcoming Geothermal Vision Study should address these shortcomings. Land-fill gas generators are not a technology allowed in ReEDS beyond what is prescribed because we have no land-fill gas resource assessment in ReEDS that would say how much resource exits across the country. Biomass and CSP were found to be less cost-competitive than other options in ReEDS. Actual biomass plants that are built usually have site-specific benefits not captured in ReEDS (e.g., a biomass plant that uses waste fuel at low cost). In the case of CSP, new plants were built with higher expected performance or lower expected costs.

Figure 7 shows the buildout of the various technologies from 2012-2016. In general, the Revised scenario has wind capacity coming online later than in the Prescribed scenario. In 2012, there was a significant rush to complete wind projects before the expiration of the production tax credit. Because ReEDS does not have policy foresight, it could not see that expiration and choose to build capacity before the incentive expired. By 2016, however, the total wind capacity is nearly the same. This result demonstrates that ReEDS results are often more robust when aggregated over time rather than looking at a single year (e.g., cumulative builds through 2030 is a more robust result than what was built in 2030). 


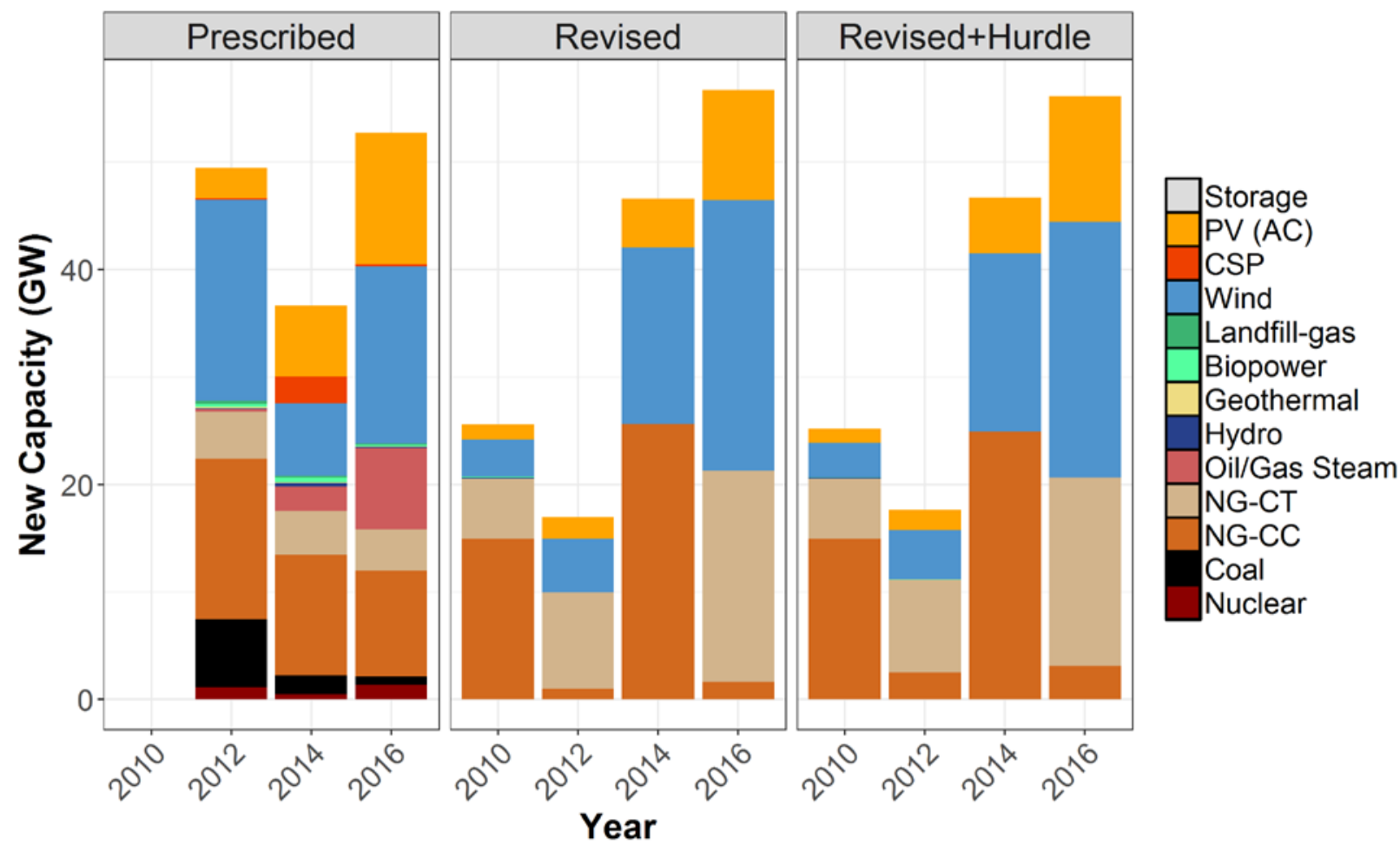

Figure 7. New capacity additions by year, technology, and scenario ${ }^{5}$

Figure 8 show the state-level distribution of the ReEDS results. The model prefers to build wind in the upper Midwest (Montana, North Dakota, and Wyoming). These three states have very high-quality wind resources. In addition, North Dakota has an investment tax credit for new wind plants. Wind in Texas is underestimated, in part because of the over-building of natural gas plants (Figure 8) in ERCOT. ERCOT is essentially the only region whose reserve margin is near or below the NERC-recommended planning reserve margin level, so by using the long-term interconnect average reserve margin, there is additional incentive to add natural gas combinedcycle units, which in turn reduces the value of new wind capacity. In general, the state-level wind results improve with the addition of a $\$ 10 / \mathrm{MWh}$ hurdle rate, indicating that a stricter transmission implementation can improve the spatial accuracy of the model.

\footnotetext{
${ }^{5}$ ReEDS models 2010 , but does so with the 2010 capacity already installed and thus does not have any new builds in the Prescribed scenario. The new builds occurring in the Revised scenarios are therefore above what was installed, and are driven in large part by the higher planning reserve margin.
} 

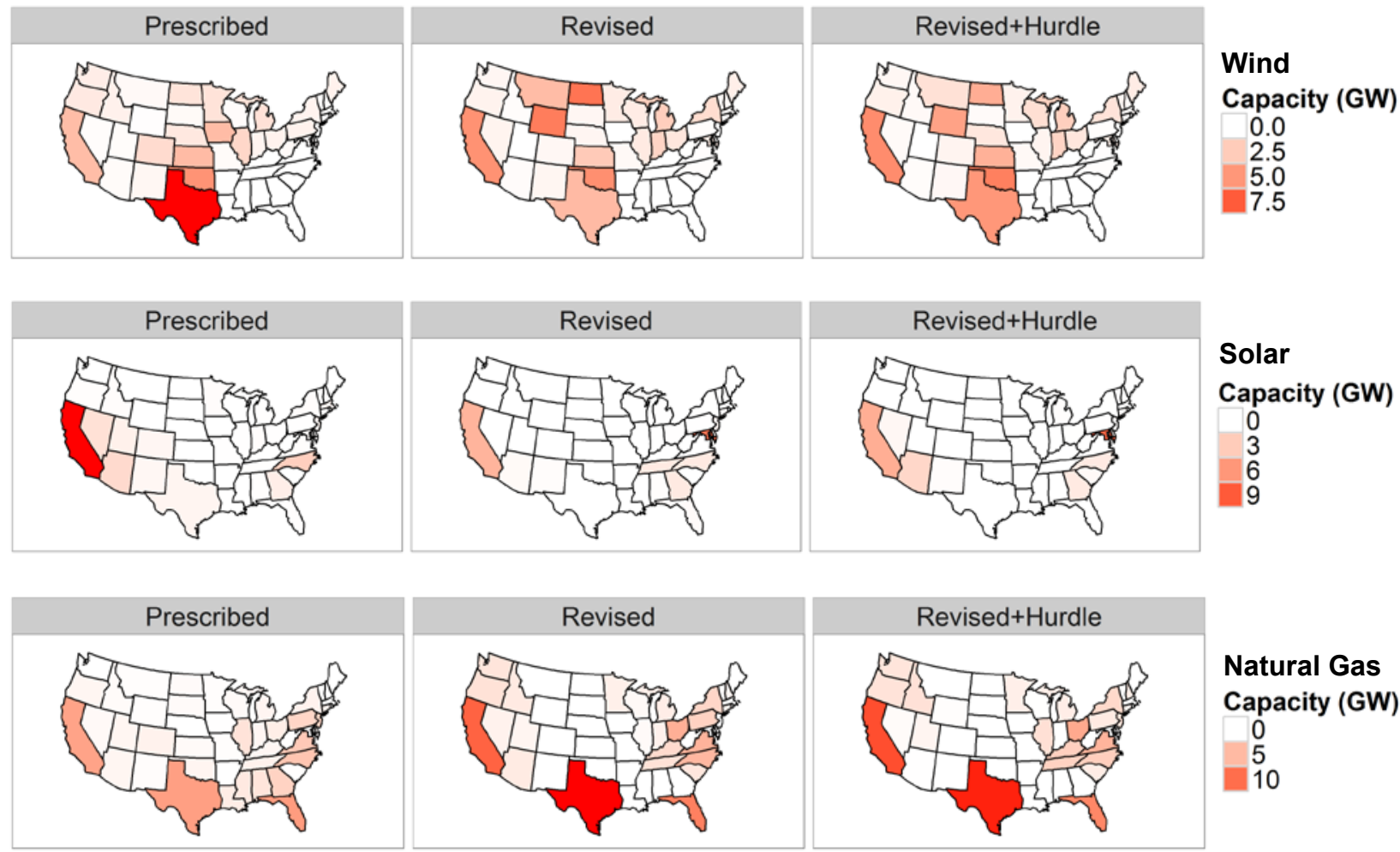

Figure 8. Wind (top), solar (middle) and natural gas capacity added from 2010-2016 by state for Prescribed (left), Revised (middle), and Revised+Hurdle (right) scenarios. Note differences in scales.

Solar capacity is underpredicted in California for two primary reasons: 1) California exceeded its RPS requirement by several percentage points, whereas the Revised scenarios only built out to the minimum PRS requirement, and 2) ReEDS did not find CSP to be a cost-effective option, building extra wind instead of the CSP. With respect to the overcompliance of the California RPS, ReEDS does not have policy foresight to see that the RPS is going to increase (coupled with the anticipated 2016 expiration of the solar investment tax credit), nor does ReEDS have REC banking as an option, so the model does not see any benefit in exceeding the California RPS through 2016. State-level solar deployments in the Southwest also improve with the inclusion of the $\$ 10 / \mathrm{MWh}$ hurdle rate.

Figure 9 and Figure 10 show the total installed capacity and the capacity installed from 20102016 in all seven scenarios. These figures illustrate how the various changes we implemented for the Revised scenario impacted model results. With no changes (Default), ReEDS builds very little new capacity because the system is overbuilt relative to the NERC-recommended reserve margin levels. Updating the planning reserve margins in ReEDS to use the long-term interconnect average values (refer back to Figure 2) results in substantially more capacity getting built. Changes in finance rates (from a long-term average to a short-term average) and in the availability of low-cost geothermal, hydropower upgrades, and CAES result in more wind and PV development. The reduction of hydropower and geothermal increase the demand for renewable energy credits (RECs) from wind and PV, and the lower financing costs increase the 
competitiveness of wind and PV relative to natural gas generators because wind and PV are more capital intensive than NG-CC units. ${ }^{6}$

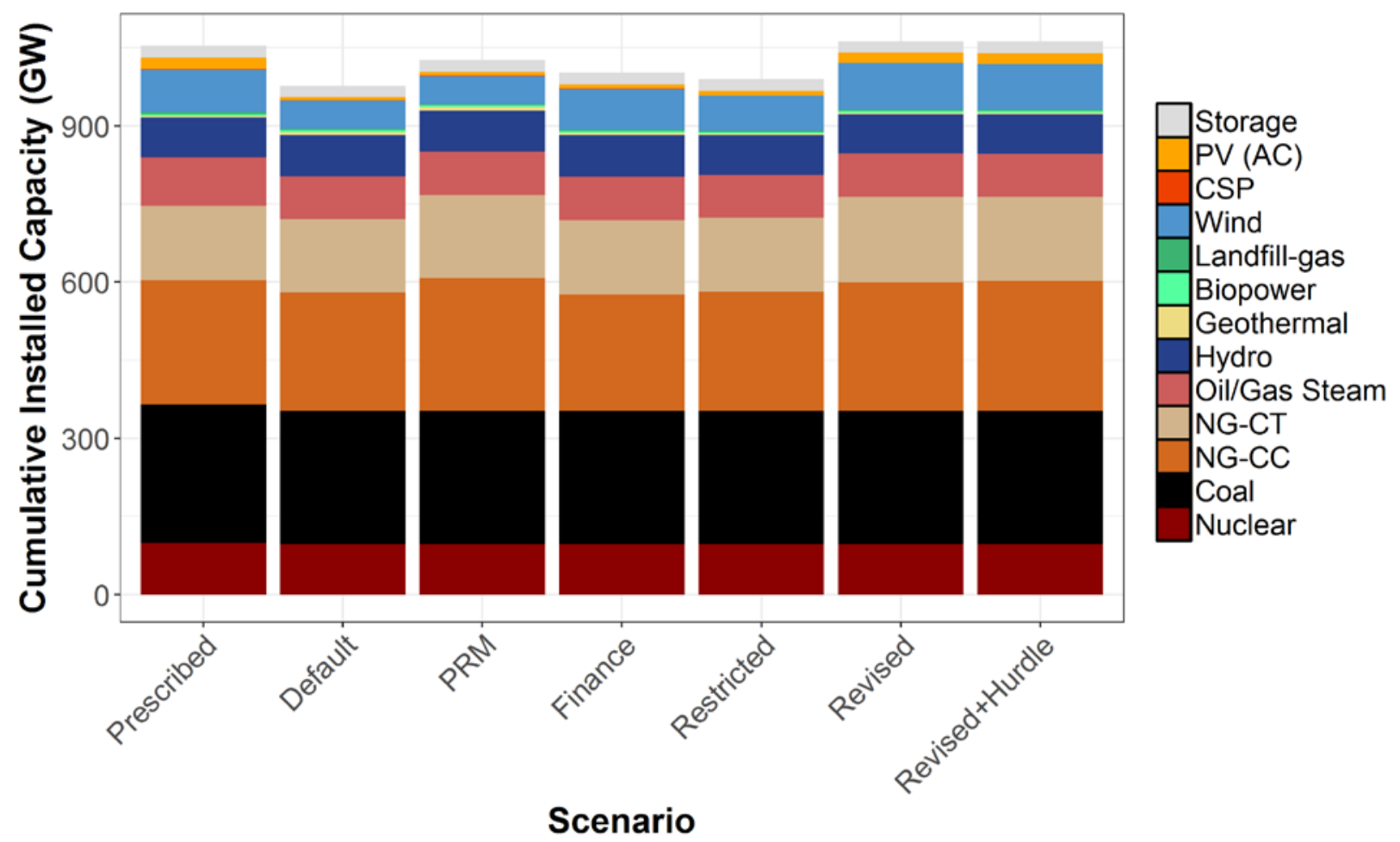

Figure 9. Final installed capacity of all scenarios

\footnotetext{
${ }^{6}$ Because financing costs impact the capital cost of a plant and not the fuel cost of a plant, the total system cost of
} wind and PV are more sensitive to financing costs than NG-CC units because wind and PV have no fuel costs. 


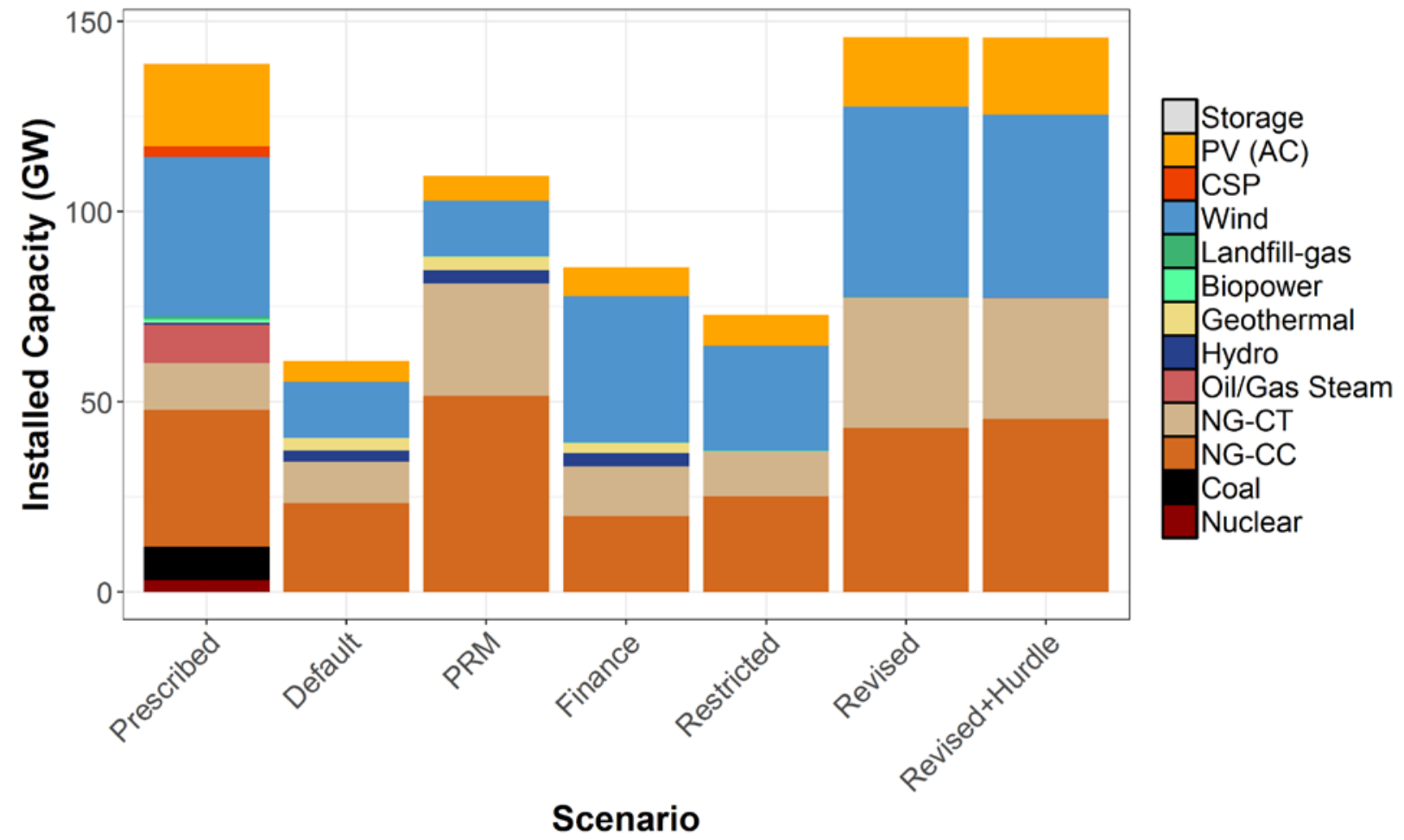

Figure 10. Capacity installed from 2010-2016 


\section{Discussion}

As seen in the results, one fundamental driver of a model being able to reproduce actual builds is whether or not the model is using the best inputs and assumptions. In its default configuration, ReEDS performed poorly in reproducing actual builds, but as key assumptions were modified, that gap was closed substantially. Additional refinement of assumption and inputs, such as the inclusion of region-specific foresight or nuclear uprates, would likely lead to improvements in accuracy. However, additional model features come with added cost and complexity including the costs from the creation and maintenance of the capability, and the complexity from the increased difficulty in interpreting results while additional drivers are impacting the results.

The goal of this work was not perfect replication of historical grid buildout. ReEDS does not serve as a prediction tool, but rather as an analysis tool where scenarios are typically compared to one another rather than evaluated in isolation. This way of using the tools means that being able to capture the appropriate drivers rather than the exact place and time of the builds tends to be more important. Therefore, the goals of this exercise were to understand what features were missing from ReEDS that might impact long-term solutions, and to provide some quantitative understanding about whether the ReEDS model is capturing overall power sector investment behavior and trends. We identify additional potential drivers of power sector modeling in the Summary and Conclusions section below, but we did not pursue these additional drivers because 1) the Revised scenario buildout was sufficiently close to the Prescribed scenario as to not give us cause for concern in the solution, and 2) the cost of adding and testing many of these features is high, and it is unclear how many of them would be incorporated into the ReEDS forwardlooking projections (as opposed to being used only to test historical years). 


\section{Summary and Conclusions}

In this work we compared the capacity expansion decisions from the ReEDS model for 20102016 against historical build decisions for the contiguous U.S. electricity sector. We found that with the changes implemented, ReEDS was able to reproduce the 2010-2016 buildout with reasonably high accuracy, especially given the large amount of assumptions that were not matched to historical data. The changes that were implemented highlight areas where the ReEDS model can and should be improved:

- Planning reserve margins. ReEDS has traditionally used the NERC-recommended planning reserve margin level for all years, but this validation exercise has demonstrated that using these planning reserve margin levels are insufficient to reproduce historical buildout. We have already implemented this change in ReEDS (Reimers, Cole, and Frew under review2019).

- Financing rates. ReEDS has always used long-term average financing rates for inputs, but these rates are significantly higher than current rates. We are currently working on incorporating annual financing rates into ReEDS that will allow the current low rates to ramp up to long-term average rates over time.

- Hydropower upgrade, geothermal, and CAES supply curves. The lowest cost resources on the hydropower upgrade, geothermal and CAES supply curves as so low cost that they get built as soon as the model is allowed to build them. These costs are not necessarily wrong; often there are other factors that restrict the timing of deploying what appears to be a cost-effective resource. The hydropower upgrades are addressed in ReEDS by staging in the available capacity gradually over time based on relicensing schedules (DOE 2016). The geothermal supply curves have been updated as part of the forthcoming Geothermal Vision Study, and those new supply curves address the too-lowcost issues seen here. And the CAES supply curve cost have been based on a Black \& Veatch cost report (Black \& Veatch 2012), but through this exercise we are updating those CAES input costs based on a more recent study done by Lazard (Lazard 2016).

The state-level results showed that the ReEDS results were somewhat improved by adding a cost penalty for moving power between regions, indicating that the overall ReEDS transmission treatment is likely too generous. We have ongoing work to address the treatment of transmission in ReEDS and anticipate that that work will identify how ReEDS transmission should be updated to capture possible flows between regions.

In addition to these key areas of improvement listed above, we also found a number of additional areas where the model could be improved:

- Inclusion of foresight, especially for policies, would lead to an improved solution, especially with respect to the timing of builds. For example, ReEDS underpredicts the wind deployment that occurred in 2012 due to the expiring tax credit, but it could capture that buildout with appropriate foresight.

- $\quad$ REC trading rules can have a large impact on state decisions, but ensuring that all rules are appropriately represented is challenging both in data collection and model implementation. Some resources exist, but because of the continuous evolution of the RPS policies, maintaining the rules over time is a challenge. 
- ReEDS gives all technologies the same financing costs, but in reality, each technology has different risk profiles and potential investors that lead to a range of financing costs.

- Several build decisions over the past few years, such as the Watts Bar nuclear power plant, are very site or situation specific. Insofar as these specific considerations can be identified, their incorporation can lead to improved results.

- Because ReEDS does not model endogenous retirements, we can only evaluate new build decisions in this exercise. However, retirement decisions are a key aspect of capacity expansion and inclusion of retirement decisions could lead to better model projections.

- Nuclear uprates and coal-to-gas switching are not endogenously modeled in ReEDS and thus can never be chosen as technology options. Inclusion of these technology options would lead to more robust solutions.

- ReEDS only includes "large-scale" state incentives that would apply to many large-scale plants. For example, an incentive that would only apply to plants of size $1 \mathrm{MW}$ or smaller would be excluded from ReEDS on basis of scale. However, a number of states have smaller-scale incentives that impact decisions to build new generators. Representing these incentives would improve state-level results.

- ReEDS does not allow for REC banking to meet future RPS requirements, and therefore does not see value in exceeding RPS requirements from 2010-2016 in states like California.

Overall, we have found the model validation exercise performed here to be important for identifying areas of improvement for the ReEDS model and in giving us confidence in the ReEDS capacity expansion decisions. 


\section{References}

ABB. 2017. "ABB Velocity Suite.” 2017. http://new.abb.com/enterprise-software/energyportfolio-management/market-intelligence-services/velocity-suite.

Beiter, Philipp, Wesley J. Cole, and Daniel C. Steinberg. 2017. "Modeling the Value of Integrated U.S. and Canadian Power Sector Expansion." The Electricity Journal 30 (2): 47-59. https://doi.org/10.1016/j.tej.2017.01.011.

Black \& Veatch. 2012. "Cost and Performance Data for Power Generation Technologies." Overland Park, KS: Black \& Veatch Corporation. https://www.bv.com/docs/reports-studies/nrelcost-report.pdf.

Bolinger, Mark, Joachim Seel, and Kristina LaCommare. 2017. "Utility-Scale Solar 2016: An Empirical Analysis of Project Cost, Performance, and Pricing Trends in the United States." LBNL-2001055. Berkeley, CA: Lawrence Berkeley National Laboratory. https://emp.lbl.gov/sites/default/files/utility-scale_solar_2016_report.pdf.

Cole, Wesley, Bethany Frew, Pieter Gagnon, James Richards, Yinong Sun, Jarett Zuboy, and Robert Margolis. 2017. "SunShot 2030 for Photovoltaics (PV): Envisioning a Low-Cost PV Future.” NREL/TP-6A20-68105. Golden, CO: National Renewable Energy Laboratory. https://www.nrel.gov/docs/fy17osti/68105.pdf.

Cole, Wesley, Haley Lewis, Ben Sigrin, and Robert Margolis. 2016. "Interactions of Rooftop PV Deployment with the Capacity Expansion of the Bulk Power System." Applied Energy 168 (April): 473-81. https://doi.org/10.1016/j.apenergy.2016.02.004.

Cole, Wesley, Trieu Mai, Paul Donohoo-Vallett, James Richards, and Paritosh Das. 2017. "2017 Standard Scenarios Report: A U.S. Electricity Sector Outlook.” Technical Report NREL/TP6A20-68548. Golden, CO: National Renewable Energy Laboratory. https://www.nrel.gov/docs/fy18osti/68548.pdf.

Cole, Wesley, Trieu Mai, Kelly Eurek, Daniel C. Steinberg, and Robert Margolis. 2015. "Considering the Role of Solar Generation under Rate-Based Targets in the EPA's Proposed Clean Power Plan." The Electricity Journal 28 (8): 20-28. https://doi.org/10.1016/j.tej.2015.09.002.

DOE. 2012. "SunShot Vision Study." DOE/GO-102012-3037. Washington, D.C.: U.S. Department of Energy. http://www.nrel.gov/docs/fy12osti/47927.pdfDOE/GO-102012-3037.
- 2015. "Wind Vision: A New Era for Wind Power in the United States." DOE/GO- 102015-4557. Washington, D.C.: U.S. Department of Energy. http://www.energy.gov/sites/prod/files/WindVision_Report_final.pdf.

\footnotetext{
Source." Technical Report DOE/GO-102016-4869. Washington, D.C.: U. S. Department of Energy. http://energy.gov/eere/water/articles/hydropower-vision-new-chapter-america-s-1strenewable-electricity-source.
} 
Donohoo-Vallett, Paul, Trieu Mai, Matthew Mowers, and Gian Porro. 2017. "Impact of Clean Energy R\&D on the U.S. Power Sector.” NREL/TP--6A20-67691. Golden, CO: National Renewable Energy Laboratory. https://www.osti.gov/scitech/biblio/1340173.

Eurek, Kelly, Wesley Cole, David Bielen, Stuart Cohen, Bethany Frew, Jonathan Ho, Venkat Krishnan, Trieu Mai, and Daniel Steinberg. 2016. "Regional Energy Deployment System (ReEDS) Model Documentation: Version 2016." NREL/TP-6A20-67067. Golden, CO: National Renewable Energy Laboratory. http://www.nrel.gov/docs/fy17osti/67067.pdf.

Frew, Bethany, Wesley Cole, Yinong Sun, James Richards, and Trieu Mai. 2017. "8760-Based Method for Representing Variable Generation Capacity Value in Capacity Expansion Models." NREL/CP-6A20-68869. Golden, CO: National Renewable Energy Laboratory. https://www.nrel.gov/docs/fy17osti/68869.pdf.

Fu, Ran, David J. Feldman, Robert M. Margolis, Michael A. Woodhouse, and Kristen B. Ardani. 2017. "U.S. Solar Photovoltaic System Cost Benchmark: Q1 2017.” NREL/TP-6A20-68925. Golden, CO: National Renewable Energy Laboratory. https://doi.org/10.2172/1390776.

Gagnon, Pieter, Wesley J. Cole, Bethany Frew, and Robert Margolis. 2017. "The Impact of Retail Electricity Tariff Evolution on Solar Photovoltaic Deployment." The Electricity Journal, Energy Policy Institute's Seventh Annual Energy Policy Research Conference, 30 (9): 22-28. https://doi.org/10.1016/j.tej.2017.10.003.

Lazard. 2016. "Lazard's Levelized Cost of Storage - Version 2.0." https://www.lazard.com/media/438042/lazard-levelized-cost-of-storage-v20.pdf.

Mai, Trieu, Wesley Cole, Eric Lantz, Cara Marcy, and Benjamin Sigrin. 2016. "Impacts of Federal Tax Credit Extensions on Renewable Deployment and Power Sector Emissions." NREL/TP-6A20-65571. Golden, CO: National Renewable Energy Laboratory. http://www.nrel.gov/docs/fy16osti/65571.pdf.

Mai, Trieu, R. Wiser, D. Sandor, G. Brinkman, G. Heath, P. Denholm, D. J. Hostick, N. Darghouth, A. Schlosser, and K. Strzepek. 2012. "Exploration of High-Penetration Renewable Electricity Futures. Vol. 1 of Renewable Electricity Futures Study." NREL/TP-6A20-52409-1. Golden, CO: National Renewable Energy Laboratory. https://www.nrel.gov/docs/fy12osti/52409-1.pdf.

Mai, Trieu, Ryan Wiser, Galen Barbose, Lori Bird, Jenny Heeter, David Keyser, Venkat Krishnan, Jordan Macknick, and Dev Millstein. 2016. "A Prospective Analysis of the Costs, Benefits, and Impacts of U.S. Renewable Portfolio Standards." NREL/TP--6A20-67455; LBNL-1006962. Golden, CO: National Renewable Energy Laboratory. https://www.osti.gov/scitech/biblio/1337612-prospective-analysis-costs-benefits-impactsrenewable-portfolio-standards.

NREL. 2017. “2017 Annual Technology Baseline.” Golden, CO: National Renewable Energy Laboratory. http://www.nrel.gov/analysis/data_tech_baseline.html. 
Reimers, Andrew, Wesley J. Cole, and Bethany A. Frew. under review2019. "The Impact of Planning Reserve Margins in Long-Term Planning Models for the Electricity Sector." Energy Policy 135: 1-8. https://doi.org/10.1016/j.enpol.2018.10.025.

Short, Walter, Nate Blair, Donna Heimiller, and Vikram Singh. 2003. "Modeling the Long-Term Market Penetration of Wind in the United States." NREL/CP-620-34469. Golden, CO: National Renewable Energy Laboratory. http://www.nrel.gov/docs/fy03osti/34469.pdf.

Sigrin, Benjamin, Michael Gleason, Robert Preus, Ian Baring-Gould, and Robert Margolis. 2016. "The Distributed Generation Market Demand Model (DGen): Documentation." NREL/TP-6A2065231. Golden, CO: National Renewable Energy Laboratory.

http://www.nrel.gov/docs/fy16osti/65231.pdf.

Wiser, Ryan, and Mark Bolinger. 2017. “2016 Wind Technologies Market Report.” Department of Energy.

https://energy.gov/sites/prod/files/2017/08/f35/2016_Wind_Technologies_Market_Report_0.pdf. 


\section{Appendix}

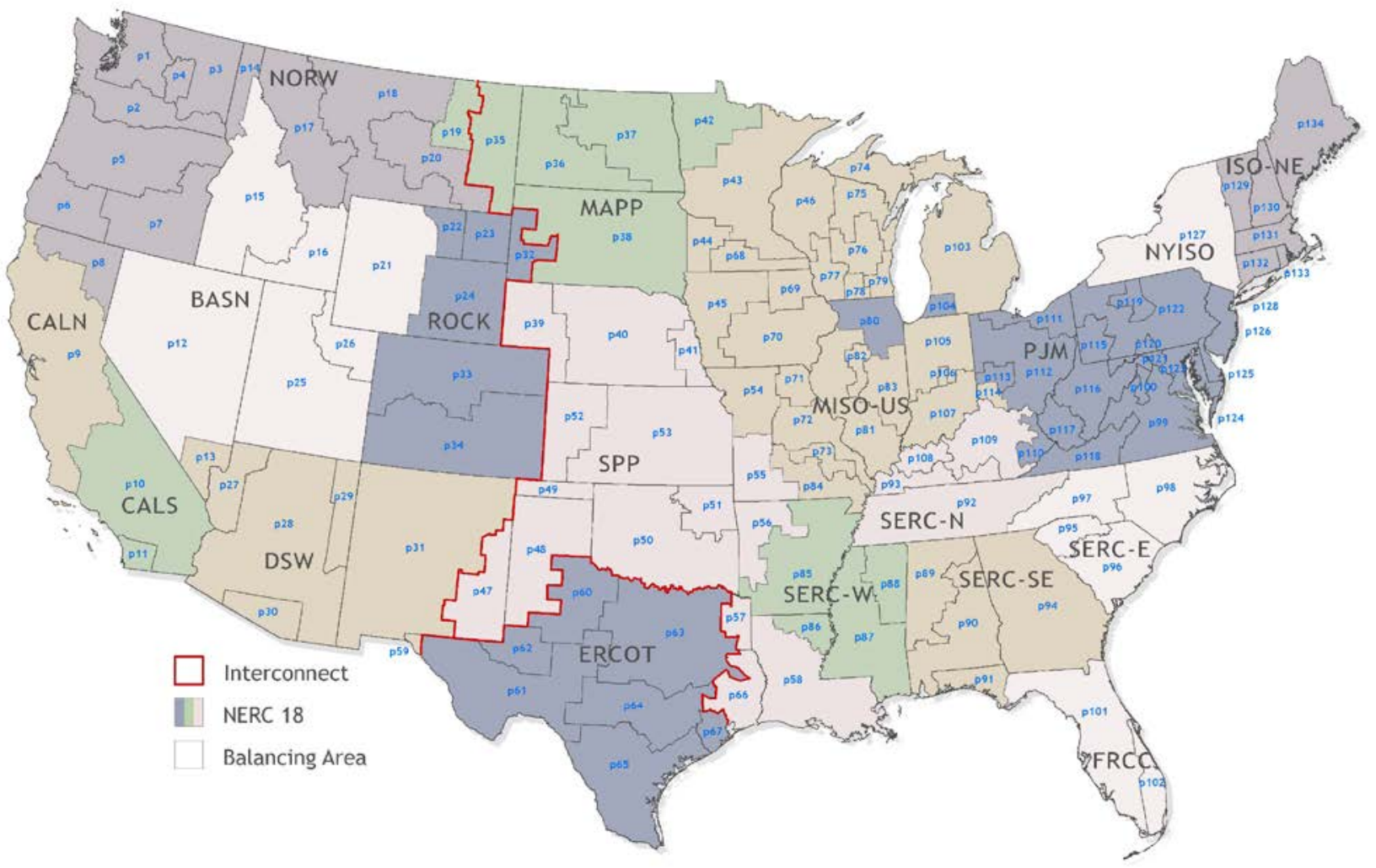

Figure 11. Map of the "NERC" regions at which the planning reserve margin is specified.

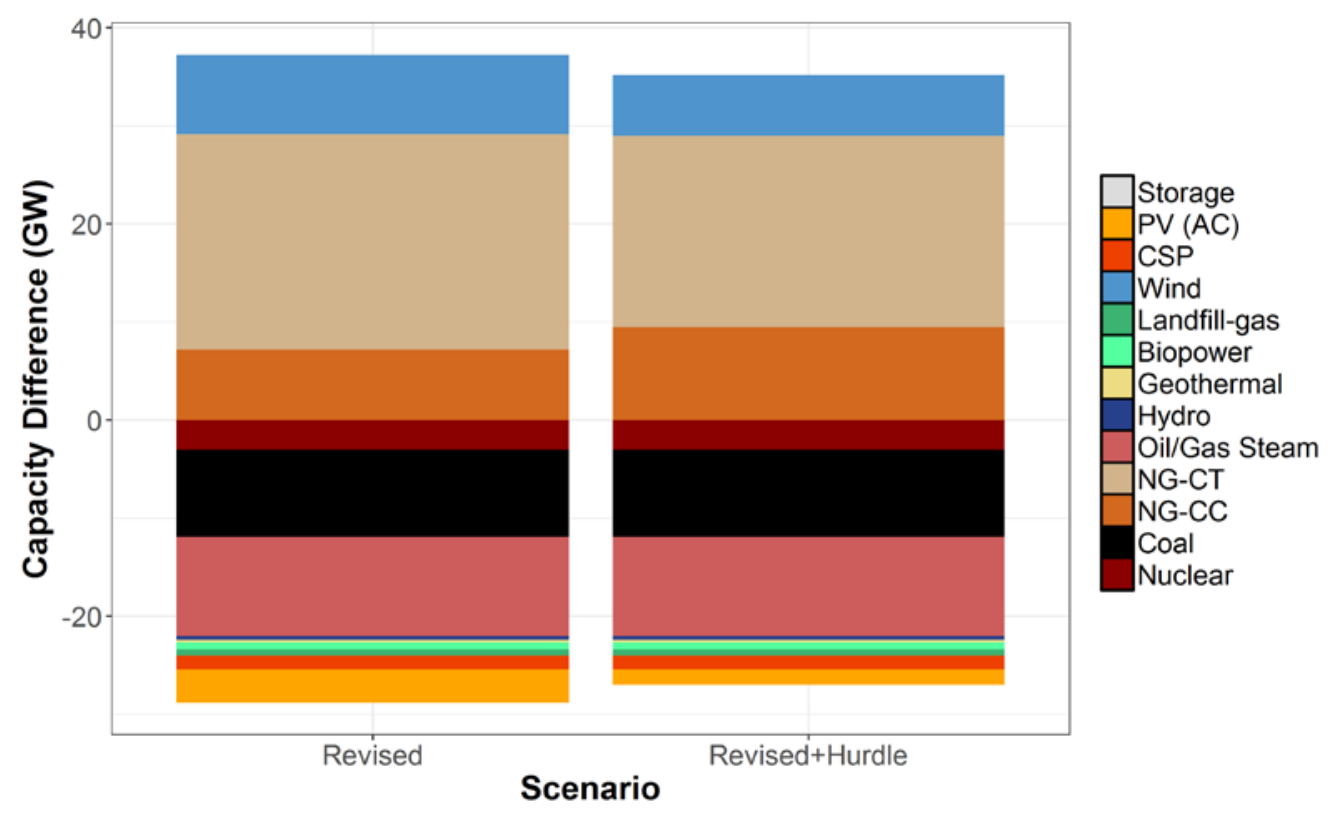

Figure 12. Difference between the selected scenarios and the Prescribed Scenario. 